“ C 2019 IEEE. Personal use of this material is permitted. Permission from IEEE must be obtained for all other uses, in any current or future media, including

reprinting/republishing this material for advertising or promotional purposes, creating new collective works, for resale or redistribution to servers or lists, or reuse of any copyrighted component of this work in other works." 


\title{
Analysis and Design Optimization of a Permanent Magnet Synchronous Motor for a Campus Patrol Electric Vehicle
}

\author{
Xiaodong Sun, Senior Member, IEEE, Zhou Shi, Gang Lei, Member, IEEE, \\ Youguang Guo, Senior Member, IEEE, and Jianguo Zhu, Senior Member, IEEE
}

\begin{abstract}
This work presents the analysis, design and optimization of a permanent magnet synchronous motor (PMSM) for an electric vehicle $(\mathrm{EV})$ used for campus patrol with a specific drive cycle. Firstly, based on the collected data like the parameters and speed from a test EV on the campus road, the dynamic calculation of the $\mathrm{EV}$ is conducted to decide the rated power and speed range of the drive PMSM. Secondly, according to these requirements, an initial design and some basic design parameters are obtained. Thirdly, optimization process is implemented to improve the performance of the designed PMSM. The permanent magnet (PM) structure, airgap length and stator core geometry are optimized respectively in this step. Different optimization processes are proposed to meet multiple optimization objectives simultaneously. Based on the finite element analysis (FEA) method, it is found that the harmonic of the optimized PMSM is lower than that of the initial design, and the torque ripple is reduced by $24 \%$. The effectiveness of optimization on the core loss and $P M$ eddy loss is validated and the temperature rise is suppressed effectively. Finally, a prototype is fabricated for the optimized PMSM and an experimental platform is developed. The test results verify that the optimized PMSM meets the requirements of the specific campus patrol $\mathrm{EV}$ well.
\end{abstract}

Index Terms-Electric vehicles, finite-element analysis, optimization, permanent magnet synchronous motor.

\section{INTRODUCTION}

$\mathrm{T}^{\circ}$ O solve the problems such as global warming, energy shortages and noise pollution closely related to the traditional vehicles, governments, academic and industrial communities have putting great effort into the development of electric vehicles (EVs) [1-6]. The key technologies of EVs development include body design, motor drive system, energy system and management, and system-level optimization. Motor drive system is a crucial part because it is the sole power source

Copyright (c) 2019 IEEE. Personal use of this material is permitted. However, permission to use this material for any other purposes must be obtained from the IEEE by sending a request to pubspermissions@ieee.org.

Manuscript received January 07, 2019; revised May 28, 2019; accepted September 02, 2019. This work was supported by the National Natural Science Foundation of China under Project 51875261, the Natural Science Foundation of Jiangsu Province of China under Projects BK20180046 and BK20170071, the "Qinglan project" of Jiangsu Province, the Key Project of Natural Science Foundation of Jiangsu Higher Education Institutions under Project 17KJA460005, the Practice Innovation Program of Jiangsu Province under Project KYCX17_1815, in the EVs. Hence, the study on the high-performance drive motors for EVs has been a research focus for many years.

In the design process of a drive motor, the parameter matching is of great importance and was studied in several papers [5-9]. In [10], a permanent-magnet (PM) traction motor based on magneto static finite-element analysis (FEA) was proposed based on NEDC. In [11], a new magnetic-planetarygeared PM motor for hybrid electric vehicles (HEVs) was presented. By integrating a magnetic planetary gear into PM machine, the motor can achieve both power split and mixing flexibly. The new motor structure promises ultralow emission and high fuel efficiency at different operational modes. In [12], the design and optimization based on coupled lumped thermal and magnetic networks for Rare-Earth-Free PM synchronous reluctance machine (SynRM) was combined with Worldwide Harmonized Light-duty Test Procedure (WLTP) drive cycle. These researches improved the drive system performance of the EVs based on the analysis of determined drive cycles. However, these drive cycles are not suitable for some situations especially when the drive motor is designed for EVs as their drive cycles are quite different from the NEDC. In this case, the main design parameters of the driving motor need to be matched with the drive cycle and the transmission system. Therefore, a PMSM is designed and optimized for an EV used for the campus patrol in this work with consideration of the practical drive cycle and road condition obtained from a test EV.

To improve the performance of EVs, many researches have focused on the structural design and control methods of the drive motors [13-15]. Initially, the DC motor drive system was adopted in EVs, but the commutator and brush of the DC motor need regular maintenance. Nowadays, with the development of motor control technologies, computer technologies and PM material, many advanced motor drive technologies show better

and the Six Categories Talent Peak of Jiangsu Province under Project 2015-XNYQC-003. (Corresponding author: Gang Lei.)

$X$. Sun and Z. Shi are with the Automotive Engineering Research Institute, Jiangsu University, Zhenjiang 212013, China (email: xdsun@ujs.edu.cn, shizhoujiangda@163.com).

G. Lei and Y. Guo are with the School of Electrical and Data Engineering, University of Technology Sydney, Sydney, NSW 2007, Australia (e-mail: Gang.Lei@uts.edu.au, Youguang.Guo$1 @ u t s . e d u . a u)$.

J. Zhu is with the School of Electrical and Information Engineering, University of Sydney, Sydney, NSW 2006, Australia (e-mail: jianguo.zhu@sydney.edu.au). 
performance than DC motors, such as induction motors, switched reluctance motors and permanent magnet synchronous motors (PMSMs) [16]. Among them, PMSM drives might be the most attractive motor drives for EV propulsion currently. Their key features including high power density and high efficiency are attributed to the use of highenergy PM material [17]. They are becoming dominant in the market share of EV motor drives [18-22].

In the aspect of motor topological optimization, a large number of papers have studied the optimization of motors. Advances and trends in mathematical modeling and computer simulation, together with the availability of sophisticated optimization techniques, have opened the way to a new approach for electrical machine design. A large number of algorithms have been applied to motor optimization such as genetic algorithm (GA), differential evolution (DE), response surface methodology (RSM), grid search (GS), particle swarm optimization (PSO) [23-28].

In [23], an interior permanent magnet synchronous motor (IPMSM) was optimized by combining GA with the coarse mesh finite element method (FEM) which can automate the process and reduce the time it takes to design an IPMSM to meet such specifications. The proposed optimization method effectively improves the efficiency of optimization. In [24], a five-phase external rotor PM-SynRMs with neodymium and ferrite-based PMs was optimized through DE method. In [26], RSM was used for the optimization of a synchronous reluctance machine for flywheel energy storage system. A comprehensive optimization of rotor parameters has been carried out and the performance of the machine was well improved. In [27], Pareto optimization and NSGA-II were used on the design of a PMSM.

These optimizations can obtain the global optimal solution through a large number of calculations by using advanced optimization algorithms and methods. While the consumption of time calculation is enormous. And most optimization focus on the PMs shape, rotor parameters, and electromotive force harmonics. However, these optimization methods are usually lack of pertinence. The relationship between optimization objects and optimization objectives is not strong. In this paper, the PMs shape, airgap length, and stator core geometry are optimized respectively, and different optimization objectives are set for them respectively.

This paper is organized as follows. In section II, the size parameters and the driving system of a test EV is studied to obtain some dynamic parameters of the proposed PMSM. Section III shows the designed PMSM based on the power equation and the FEM. Some design parameters, such as PM dimensions, are optimized to meet the requirement of the output torque while reducing the cogging torque and the eddy loss in PMs. Section IV presents the performance of the motor before and after optimization by using the FEM and thermal network model. Section V presents a prototyped PMSM with tested results for verification of the motor performances, followed by the conclusion.

\section{Dynamic Calculation of the Campus Patrol EV}

In order to design a PMSM for the campus patrol EV, a key preliminary work is to calculate the output power and the speed range. These key parameters are closely related to the motor size, speed requirements, drive system of the studied EV and the road condition.

The correct determination of the PMSM parameters is very important. The motor will be overloaded for a long time if the rated power is too small. On the contrary, the motor will be underloaded if the rated power is too large, resulting in low efficiency and power factor. This is not only a waste of energy, but also an increasing the cost of the motor.

\section{A. Power parameter matching}

When calculating the rated power of the motor, it is necessary to investigate the normal operation of the EV under various conditions. In the operation, the output power of the drive motor and the EV running resistance power balance each other, so in every moment the power of the motor is equal to the power consumption of mechanical transmission power loss and all resistance to motion. Vehicle driving resistance can be divided into rolling resistance $\left(F_{\mathrm{r}}\right)$, air resistance $\left(F_{\mathrm{w}}\right)$, climbing resistance $\left(F_{\mathrm{g}}\right)$, and acceleration resistance $\left(F_{\mathrm{j}}\right)$. Hence, the total resistance of the vehicle can be expressed as

$$
\begin{aligned}
& \sum F=F_{\mathrm{r}}+F_{\mathrm{w}}+F_{\mathrm{g}}+F_{\mathrm{j}}= \\
& m g f_{\mathrm{r}} \cos \alpha+\frac{1}{2} \rho A C_{\mathrm{D}} u_{a}{ }^{2}+m g \sin \alpha+\delta m \frac{d u_{a}}{d t}
\end{aligned}
$$

where $f_{\mathrm{r}}$ is the rolling resistance coefficient, $\rho$ the air density, $C_{\mathrm{D}}$ the air drag coefficient, $\alpha$ the pavement inclination angle, $\delta$ the rotary mass conversion coefficient, and $m$ the total mass of the EV. The consumption power $\left(P_{\mathrm{e}}\right)$ of EVs can be expressed as

$$
P_{\mathrm{e}}=\frac{1}{\eta_{\mathrm{T}}}\left(\frac{m g f u_{\mathrm{a}}}{3600}+\frac{m g \sin \alpha u_{\mathrm{a}}}{3600}+\frac{C_{\mathrm{D}} A u_{\mathrm{a}}^{3}}{76140}+\frac{\delta m}{3600} \frac{d v}{d t} u_{\mathrm{a}}\right)
$$

where $u_{\mathrm{a}}$ is the speed of the EV and $\eta_{\mathrm{T}}$ the transmission efficiency. The rated power $(P)$ of the PMSM should meet the requirements of the maximum speed, acceleration time and the climbing ability. Therefore, the rated power should meet the follow requirements.

$$
\begin{array}{r}
P \geq P_{\text {emax }} \\
P_{\text {max }}=\lambda P
\end{array}
$$

where $\lambda$ is the overload factor of the motor.

\section{B. Transmission Parameter Matching}

For a traditional vehicle, the power is transmitted from the engine to the wheels. For EVs, the batteries output electrical energy to the motor, and the motor generates a driving force to drive the vehicle. The driving force of the vehicle can be expressed as

$$
F_{\mathrm{t}}=\frac{T_{\mathrm{t}}}{r_{\mathrm{d}}}=\frac{T_{\mathrm{m}} i_{0} \eta_{\mathrm{t}}}{r_{\mathrm{d}}}
$$


where $F_{t}$ is the force on the wheel from the ground, $T_{\mathrm{t}}$ the torque motor acting on the driving wheel, $r_{\mathrm{d}}$ the wheel radius, $T_{\mathrm{m}}$ the motor torque, $i_{\mathrm{g}}$ the transmission ratio, $i_{0}$ the main reduction ratio, and $\eta_{\mathrm{t}}$ the mechanical efficiency of transmission system. The $u_{\mathrm{a}}$ can be given as

$$
u_{\mathrm{a}}=\frac{\pi n r_{\mathrm{d}}}{30 i_{0}}
$$

where $n$ is the rotational speed of the motor. The rated speed, maximum speed, and the minimum stable speed of the proposed motor can be calculated through (6) with the highest speed, the minimum stable speed of the test vehicle, the reduction ratio of the transmission system, and the transmission ratio of each gear.

\section{Vehicle Driving Cycle}

In the design progress of drive motors for EVs, the NEDC are usually employed as the road condition requirements. However, in this study the PMSM is design for a campus patrol EV which is different from the NEDC obviously. The design requirements related to the driving cycle closely. The influence of drive cycle on the motor design is obvious. An inappropriate drive cycle will have a negative impact on the final design. The negative impact mainly manifested in the selection of motor efficient area and maximum design torque. Different drive cycles have different high frequency working condition. In the process of motor design, it is necessary to adjust the high efficiency area of motor to match the high frequency working condition. The mismatch of the high efficiency area of motor and the high frequency working condition of the campus patrol EV will lead to lower overall efficiency and will cause higher loss which will lead to extra temperature rise in the motor. Besides, the maximum design torque is mainly based on the miniature EV parameters, the maximum acceleration, and the maximum pavement inclination angle of the road. A low maximum design torque cannot meet the dynamic requirements of $\mathrm{EV}$, and a high maximum design torque will increase the volume of the motor.

Therefore, it is necessary to sample the working conditions of the patrol EV. As the inconvenience of the pavement inclination angle value sampling, the altitude is sampled, and the pavement inclination angle can be calculated. In addition, high frequency working condition of the motor can be calculated more accurate by sampling both speed and pavement inclination angle.

Fig. 1 shows the test campus patrol EV. The speed and torque requirements are investigated for this $\mathrm{EV}$ by recording an actual drive cycle of a car route in a campus road. Fig. 2 illustrates the recorded data for the speed profile of the car route in the road around Jiangsu University. As shown, the average speed of this road could reach $60 \mathrm{~km} / \mathrm{h}$. In addition, the total length of this road is $8 \mathrm{~km}$ and the maximum track gradient of this road is $6 \%$.

\section{Motor rating data selection}

Based on above discussions and the parameters of the EV listed in Table I, the required power of the motor is calculated and shown in Table II. In addition, the acceleration of this EV with the output power increased from $6 \mathrm{~kW}$ to $18 \mathrm{~kW}$ is shown in Fig. 3.

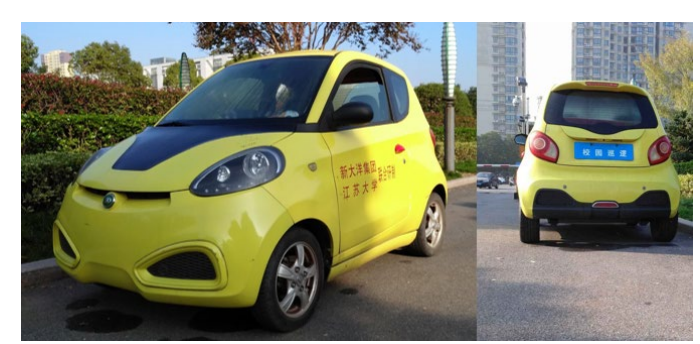

Fig. 1. A campus patrol EV for road test.

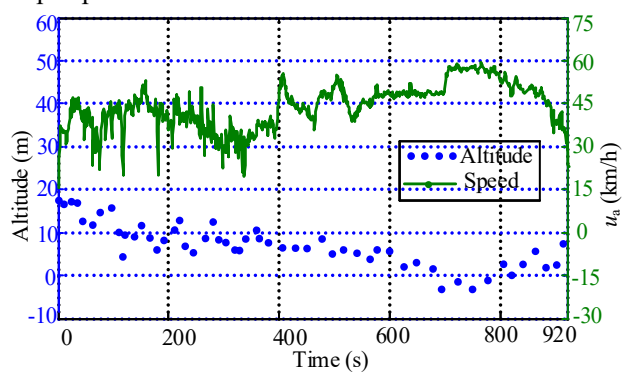

Fig. 2. Speed and altitude profiles of the EV route. TABLE I

MiniATURE EV PARAMETERS

\begin{tabular}{cccc}
\hline \hline Parameters & Symbol & Uint & Value \\
\hline Total mass of the EV & $M$ & $\mathrm{~kg}$ & 700 \\
Front cross-sectional area & $A$ & $\mathrm{~m}^{2}$ & 2.3 \\
Air drag coefficient & $C_{\mathrm{D}}$ & & 0.34 \\
Rolling friction coefficient & $f$ & & 0.015 \\
Radius of wheel & $r_{\mathrm{d}}$ & $\mathrm{mm}$ & 245 \\
Reduction ratio & $i_{0}$ & & 4.8 \\
\hline
\end{tabular}

TABLE II

MAIn Design SPECIFICATION AND PARAMETERs OF THE MOTOR

\begin{tabular}{cccc}
\hline \hline Parameters & Symbol & Uint & Value \\
\hline Work Voltage & $U_{\mathrm{N}}$ & $\mathrm{V}$ & 72 \\
Rated Power & $P_{\mathrm{N}}$ & $\mathrm{kW}$ & 9 \\
Max Torque & $T_{\mathrm{MAX}}$ & $\mathrm{N} \cdot \mathrm{m}$ & 90 \\
Rated Speed & $n_{\mathrm{N}}$ & $\mathrm{r} / \mathrm{min}$ & 2500 \\
Max Rotating Speed & $n_{\mathrm{NMAX}}$ & $\mathrm{r} / \mathrm{min}$ & 4000 \\
Pole number & $P$ & & 8 \\
Rated efficiency & $\eta$ & & 0.94 \\
\hline
\end{tabular}

As shown, the maximum speed is $65 \mathrm{~km} / \mathrm{h}$ when the output power is $6 \mathrm{~kW}$, and the maximum speed can reach $94 \mathrm{~km} / \mathrm{h}$ when the output power is $18 \mathrm{~kW}$. Considering the driving speed of the test EV and overload capacity of the PMSM, the rated power of the PMSM is set to $9 \mathrm{~kW}$.

As the campus patrol EV lacks abundant transmission ratio, higher starting torque is necessary. To ensure good aerodynamic performance, the starting motor torque is determined to be $90 \mathrm{Nm}$. Therefore, the acceleration and speed curve of the vehicle start are simulated. The EV starts with constant torque $90 \mathrm{Nm}$. When the output power reaches $12 \mathrm{~kW}$, the motor turns into constant power condition, and when the speed reaches $60 \mathrm{~km} / \mathrm{h}$, the output power decreases to $6 \mathrm{~kW}$. The acceleration and speed change curves in the start-up condition are shown in Fig. 4.

Considering the driving speed of the test EV and the transmission ratio of the transmission system, the rated speed of the motor is set to $2500 \mathrm{r} / \mathrm{min}$ and the max rotating speed is 
set to $4000 \mathrm{r} / \mathrm{min}$. The choice of pole number is related to the rotating speed and core loss. Larger pole number will lead to the increase of the core loss while smaller pole number has negative impact on the output torque ability. Based on the analysis, the pole number is set to 8 finally.

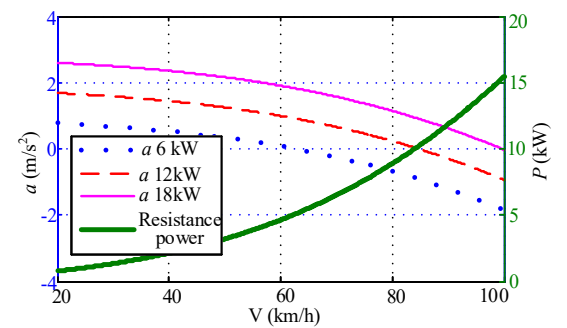

Fig. 3. Curves of acceleration at different output power and resistance power varying with speed.

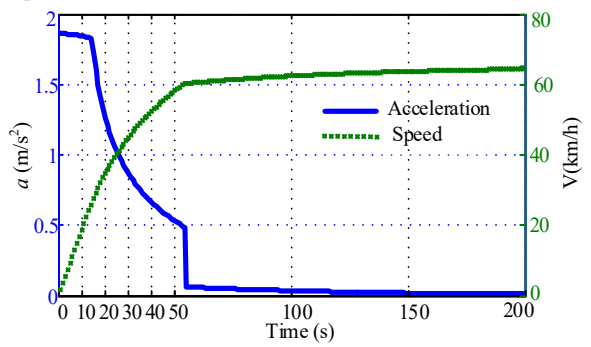

Fig. 4. Acceleration and speed curve at start-up condition.

As the campus patrol EV lacks abundant transmission ratio, higher starting torque is necessary. To ensure good aerodynamic performance, the starting motor torque is determined to be $90 \mathrm{Nm}$. Therefore, the acceleration and speed curve of the vehicle start are simulated. The EV starts with constant torque $90 \mathrm{Nm}$. When the output power reaches $12 \mathrm{~kW}$, the motor turns into constant power condition, and when the speed reaches $60 \mathrm{~km} / \mathrm{h}$, the output power decreases to $6 \mathrm{~kW}$. The acceleration and speed change curves in the start-up condition are shown in Fig. 4.

Combining the above considerations, the rated and peak powers of the motor can be chosen as $6 \mathrm{~kW}$ and $13 \mathrm{~kW}$, respectively. This promises the high efficiency at the speed of $60 \mathrm{~km} / \mathrm{h}$ and ensures the EV could reach the peak speed of 80 $\mathrm{km} / \mathrm{h}$ while keeping the ability of accelerating at the same time.

The maximum traction torque needed is estimated to be 90 $\mathrm{Nm}$. When the speed reaches $60 \mathrm{~km} / \mathrm{h}$ (the top speed in the record), the rotation speed should reach to $3120 \mathrm{r} / \mathrm{min}$. Therefore, the maximum rotation speed $4000 \mathrm{r} / \mathrm{min}$ of the motor is selected as the highest possible speed for the PMSM, which can ensure the EV to reach $75 \mathrm{~km} / \mathrm{h}$ and keep certain acceleration ability at $60 \mathrm{~km} / \mathrm{h}$. Besides, 6 and $13 \mathrm{~kW}$ are selected to be rated and peak powers of the proposed motor. The main design parameters of PMSM are shown in Table II. Moreover, some model selection parameters are also given in Table II, such as phase number, stator slots number, pole numbers, and rated efficiency.

\section{INITIAL DESIGN AND STRUCTURAL OPTIMIZATION OF THE PMSM}

The PMSM design is based on the characteristics of the motor and the parameters listed in Table II. The appropriate material is selected and is shown in Table III. The main dimension of the motor can be evaluated preliminarily based on the main design parameters and material. Then ANSYS Maxwell is used to model the motor and optimize the dimensional parameters.

Aiming to have a simple convenient manufacturing process and robust structure to withstand high-speed operation, a threephase eight-pole surface mounted-radial PMSM topology is adopted in this study. Fig. 5 shows the original threedimensional model of the PMSM. On the basis of the specifications, the geometric dimensions and parameters of this motor can be initialized as listed in Table III.

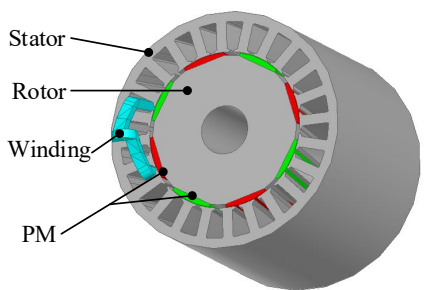

Fig. 5. Three-phase eight-pole surface mounted-radial PMSM.

TABLE III

INITIAL DESIGN OF THE PMSM

\begin{tabular}{ccc}
\hline \hline Armature diameter & $D_{a}$ & $101 \mathrm{~mm}$ \\
Core length & $L_{a}$ & $134 \mathrm{~mm}$ \\
Stator outside diameter & $D_{j}$ & $154 \mathrm{~mm}$ \\
Shaft diameter & $D_{s}$ & $31.5 \mathrm{~mm}$ \\
Slot number & $Q$ & 24 \\
Pole number & $P$ & 4 \\
Turns per slot & & 10 \\
Slot-fill factor & & 0.68 \\
Lamination material & & $\mathrm{M} 19-29 \mathrm{G}$ \\
PM material & & NdFe35 \\
\hline \hline
\end{tabular}

\section{A. PM structure}

Although the PMSM has the characteristics of high efficiency and high power density, the development of the PMSM is limited by the expensive PM material. Therefore, it is essential to use less PMs to reduce the cost without sacrificing the motor performance.

By optimizing the shape of the PMs, the utilization of PMs can be maximized. However, the shape of PM is related to the electromagnetic performance of motors closely, especially the cogging torque $\left(T_{\operatorname{cog}}\right)$, the maximum torque $\left(T_{\max }\right)$, and PM eddy losses $\left(P_{\mathrm{PM}}\right)$.

The total PM volume $V_{m}$ required for this PMSM can be estimated by [29]

$$
V_{m}=C_{V} \frac{P_{\text {in }}}{f B_{r} H_{c}}
$$

where $C_{\mathrm{V}}$ is a coefficient which ranged from 0.54 to 3.1 with a typical value of $2, P_{\text {in }}$ the input power, $f$ the input frequency, $H_{c}$ the PM coercively, and $B_{\mathrm{r}}$ the PM remanence. According to (7), the volume of each PM could be calculated. For the calculation of PM volume, Fig. 6 shows several key PM dimensions. They are the effective PM pole-arc coefficient $\alpha_{1}$ and the PM 
thickness (or height) $h_{\mathrm{m} 1} . h_{\mathrm{m} 2}$ is the thickness of the thinnest part of the PM, which requires a minimum limit to prevent the demagnetization of the PM.

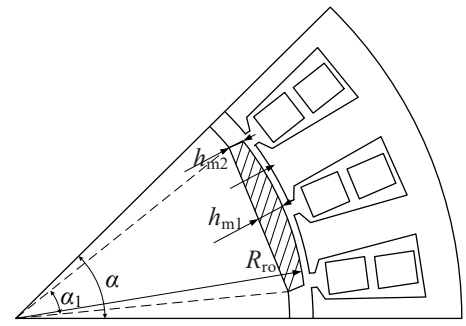

Fig. 6. Key PM dimensions of the surface mounted-radial PMSM.

In this work, the goal is to ensure the maximum torque of the motor while minimizing its cogging torque and the total volume of PMs. Apart from the $T_{\max }$ and $T_{\operatorname{cog}}$, the structure of PMs will affect the PM losses. Therefore, in the optimization process, the PM losses should be taken into consideration.

Thus, an optimization problem can be formulated as

$$
\begin{aligned}
& \max :\left\{F_{1}(x)=T_{\mathrm{max}}{ }^{2} \cdot T_{\mathrm{cog}}{ }^{-1} \cdot P_{\mathrm{PM}}{ }^{-1.5}\right\} \\
& \text { s.t. }\left\{\begin{array}{l}
\alpha_{1} \in(25,45) ; h_{\mathrm{m} 1} \in(4.5,6) \\
h_{m 2}=h_{m 1}-\left(R_{\mathrm{ro}}-R_{\mathrm{ro}} \cdot \cos \frac{\alpha_{1}}{2}\right) \geq 3.2 \mathrm{~mm} \\
V \approx 8 \cdot \alpha_{1} \cdot \frac{\pi}{180} \cdot \frac{D_{\mathrm{mo}}+D_{\mathrm{mi}}}{4} \cdot h_{\mathrm{m} 1} \cdot l \leq V_{\mathrm{m}}
\end{array}\right.
\end{aligned}
$$

where $T_{\operatorname{cog}}$ the cogging torque of the motor, $D_{\text {mo }}$ and $D_{\text {mi }}$ are the inner and outer diameters of the PMs. In this optimization step, PM pole-arc coefficient $\alpha_{1}$ and the PM thickness (or height) $h_{\mathrm{m} 1}$ will be optimized. $T_{\max }, T_{\operatorname{cog}}$, and $L_{\mathrm{PMs}}$ can be calculated through parametric FEM. In addition, in order to obtain a complete mapping between FEM outputs $\left(T_{\max }, T_{\text {cog }}, L_{\mathrm{PMs}}\right)$ and independent variables $\left(\alpha_{1}, h_{\mathrm{m} 1}\right)$, Kriging model is used to approximate the FEM [30]. Then, the optimal parameters of PMs can be obtained according to the optimization objective in (8).

\section{B. Airgap length}

Airgap is the place of the motor energy conversion. Its size and shape have great influence on motor performance, and also have a decisive impact on vibration and noise of motor. For the EV with a PMSM, due to road excitation, airgap flux density of the same pole position varies normally. Therefore, an appropriate airgap length is needed to ensure the energy conversion capability while reducing the radial electromagnetic force and maintaining the stability of the motor.

For a PMSM, the electromagnetic force acting on the rotor can be theoretically divided into radial and tangential electromagnetic forces. The tangential force causes the armature to generate torque and operate. The radial force causes the motor core to deform. The fluctuation of the radial electromagnetic force causes the vibration of the motor, thus causing the vibration and noise of the motor. According to Maxwell stress tensor theory in the air gap of the PMSM, the radial and tangential electromagnetic force $\left(f_{\mathrm{r}}\right.$ and $\left.f_{\theta}\right)$ of the unit area can be expressed as

$$
\left\{\begin{array}{l}
f_{\mathrm{r}}=\left(B_{r}{ }^{2}-B_{\theta}{ }^{2}\right) / 2 \mu \\
f_{\theta}=B_{r} B_{\theta} / 2 \mu
\end{array}\right.
$$

where $B_{\mathrm{r}}$ is the radial air gap flux density, $B_{\theta}$ the tangential air gap flux density, $\mu_{0}$ the magnetic permeability of air. According to (9), $B_{\theta}$ will not only reduce the output tangent force but also cause the rotor radial force.

The objective function can be defined as

$$
\begin{aligned}
& \max :\left\{F_{2}\left(\delta_{\text {air }}\right)=\int_{0}^{\pi} B_{\mathrm{r}}^{1.5} \cdot B_{\theta}^{-1} d \theta\right\} \\
& \text { s.t. } \delta_{\text {air }} \in(0.6,1.5)
\end{aligned}
$$

where $\delta_{\text {air }}$ is the length of the air gap, and $\theta$ is the electric angle.

The no-load radial and tangential airgap flux density are shown in Figs. 7 and 8, respectively. As shown in Fig 7, when the airgap length varies from 0.6 to $1.4 \mathrm{~mm}$, the $B_{\mathrm{r}}$ is almost the same. It means that when the airgap changes in a certain range, the change of the radial airgap flux density is limited, and the capacity of the output torque will not be affected too much. However, when the airgap length varies from 0.6 to $1.4 \mathrm{~mm}$, the amplitude of $B_{\theta}$ changes greatly. Especially, when the airgap is smaller than $1 \mathrm{~mm}$, the peak value of $B_{\theta}$ is over $0.4 \mathrm{~T}$, which will cause relatively violent motor vibration and noise. When the airgap is larger than $1 \mathrm{~mm}$, the peak value of $B_{\theta}$ is almost the same. When the airgap length reaches $1.4 \mathrm{~mm}$, the $B_{\theta}$ has an increasing tendency. According to (11), the final length of the air gap is chosen to be $1.2 \mathrm{~mm}$.

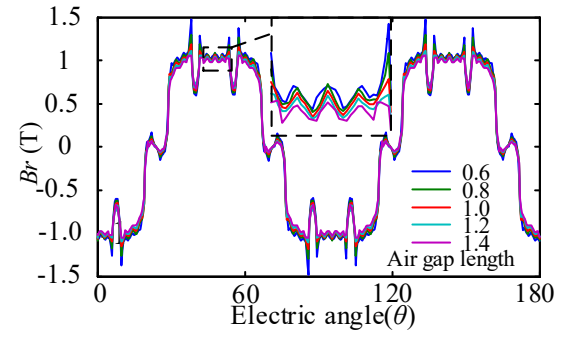

Fig. 7. No-load radial air gap flux density.

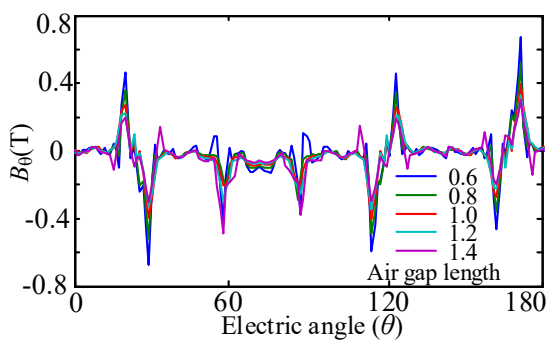

Fig. 8. No-load tangential air gap flux density.

\section{Stator structure}

When optimizing the stator structure, the sizes of the stator slot, the yoke thickness, and the tooth width are the main parameters. As long as the stator outside diameter, inner diameter and the number of slots are determined, the yoke thickness and tooth width will change with the varying of the stator slot size. Hence, in this study only the stator slot size is chosen as the optimization parameter. The structure of the stator slot and the parameters of the main dimensions are shown in Fig 9. The overall optimization procedure is shown in Fig 10. 


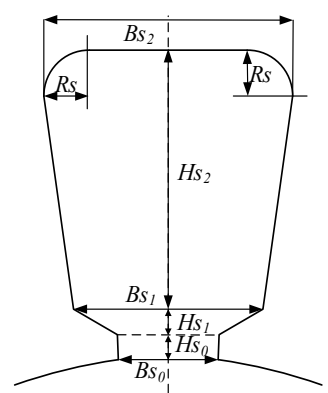

Fig. 9. Slot geometrical parameters of trapezoidal groove.

As shown in Fig. 10, firstly, some basic parameters are set. Secondly, the minimum area of the slot $\left(S_{0}\right)$ is calculated based on the number of winding turns, diameter of the wire, and rate of groove filling. Thirdly, $B s_{1}, B s_{2}$ and $H s_{2}$ are optimized. In order to ensure the consistency of tooth width, $B s_{2}$ is $2 \mathrm{~mm}$ longer than $B s_{1}$.

Moreover, as the $S_{0}$ is known, $B s_{2}$ and $H s_{2}$ can be expressed by $B s_{1}$. These parameters are the main parameters which will affect the stator core yoke and tooth width. The stator core yoke and tooth width have great effect on the core loss. Core loss in the stator can be estimated by [12]

$$
P_{\mathrm{Fe}}=K_{\mathrm{h}} f B^{1.6}+K_{\mathrm{C}} f^{2} B^{2}
$$

where $P_{\mathrm{Fe}}$ is the unit volume core loss, $K_{h}$ the hysteresis loss factor, $K_{\mathrm{c}}$ the eddy current loss factor, $B$ the flux density. With the decrease of the height of the stator core yoke, the flux density yoke magnetic circuit narrows and the yoke flux density increases. Similarly, with the decrease of the tooth width, the magnetic circuit of the tooth narrows and the core loss of the stator unit volume increases. Hence, the FEA method is used to calculate the stator parameters that can minimize the iron loss. Finally, the slot width $\left(B s_{0}\right)$ is also an important parameter which needs optimization because it has great effect on cogging torque $\left(F_{\operatorname{cog}}\right)$.

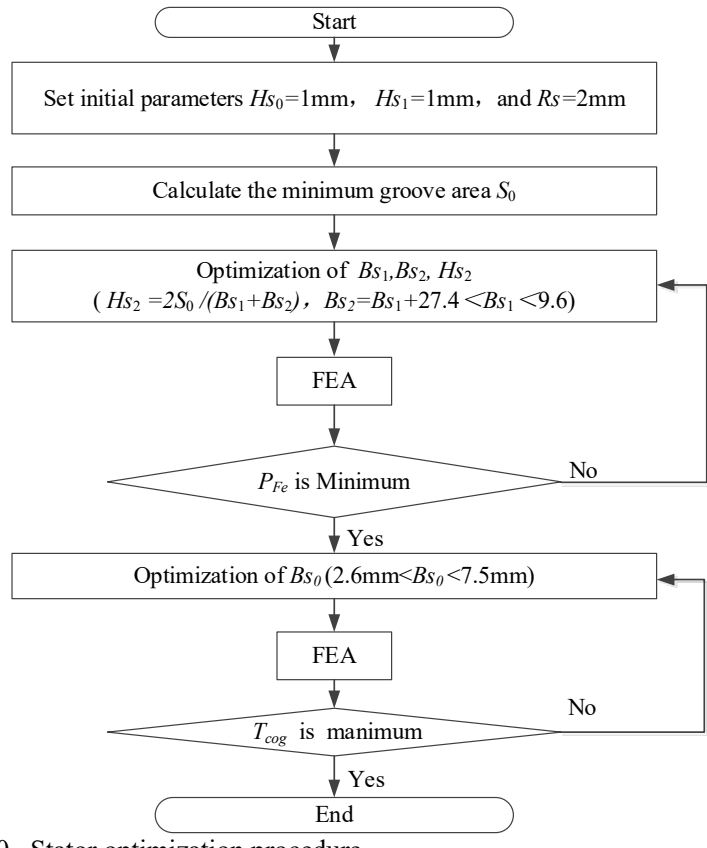

Fig. 10. Stator optimization procedure.

\section{Simulation COMPARISON OF MOTOR PERFORMANCES BEFORE AND AFTER OPTIMIZATION}

In this section, to verify the effectiveness of the optimization, the performances of the motors before and after optimization will be compared based on FEA model. Table IV lists the parameters of the initial and optimized PMSMs.

\section{A. Flux-Density Distribution}

Fig. 11 shows the open-circuit flux-density distributions of the initial and optimized motors by using FEA. As shown, the flux density of the optimized motor is $6 \%$ higher than the initial motor thanks to the optimized size of PMs. In addition, the flux density in the tooth and yoke of the stator is relative equilibrium owing to proper choice of stator slot size. The optimized motor has higher flux density than that of the original motor, which means that the torque output capability of optimized motor has been improved while the usage of the PMs is equal to the original motor.

TABLE IV

MAIN PARAMETERS OF THE INITIAL AND OPTIMIZED MOTORS

\begin{tabular}{ccccc}
\hline \hline Part & Symbol & Unit & Initial & Optimized \\
\hline \multirow{2}{*}{ PM } & $\alpha_{1}$ & $\circ$ & 31.5 & 38.2 \\
& $h_{m}$ & $\mathrm{~mm}$ & 5.1 & 4.6 \\
\cline { 2 - 5 } Air gap & $L$ & $\mathrm{~mm}$ & 0.6 & 1.2 \\
\cline { 2 - 5 } & $B s_{0}$ & $\mathrm{~mm}$ & 2.2 & 2.6 \\
Stator & $B s_{1}$ & $\mathrm{~mm}$ & 6.4 & 8.3 \\
core & $B s_{2}$ & $\mathrm{~mm}$ & 10.2 & 12.1 \\
& $H s_{2}$ & $\mathrm{~mm}$ & 17 & 15.5 \\
\hline \hline
\end{tabular}

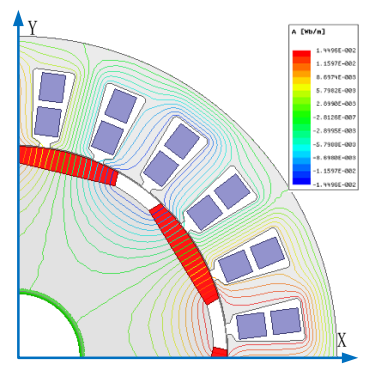

(a)

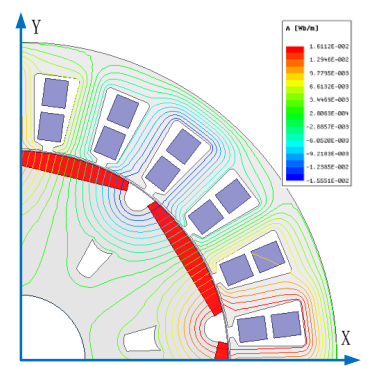

(b)
Fig. 11. Open-circuit flux-density distributions of the initial (a) and optimized (b) motors.

\section{B. Back-EMF and Cogging Torque}

The back electromotive force (EMF) waveforms of the original and optimized motors are shown in Fig. 12. The odd harmonic amplitudes are shown in Fig. 13. As shown, the value of fundamental wave of the initial motor is 3\% higher than that of optimized motor. The value of $5^{\text {th }}$ harmonic of optimized motor is obviously lower than that of the initial motor.

In order to ensure smooth operation of the EV motor, the cogging torques of two motors are also analyzed and shown in Fig. 14. As shown, the amplitudes of cogging torque of optimized motor is $24 \%$ lower than that of the original motor. The high harmonic will cause the increase of torque ripple which agrees with the cogging torque results in Fig. 14. 


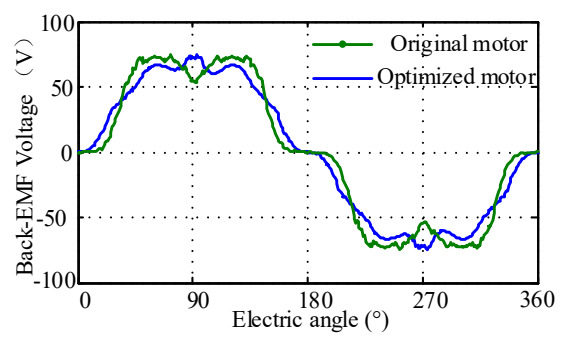

Fig. 12. Phase back-EMF waveforms of the initial and optimized motors.

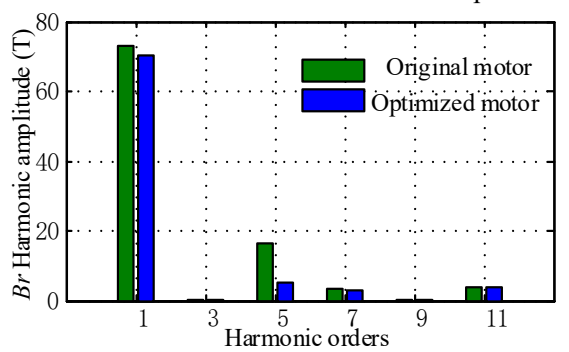

Fig. 13. Phase back-EMF harmonic spectrums of the initial and optimized motors.

\section{Core loss and PM eddy loss and Temperature rise}

The total loss of PMSM mainly includes copper loss, core loss and PM eddy loss. Since winding structure are not included in the optimization process, only the iron losses and magnetic losses are simulated and compared in this part.

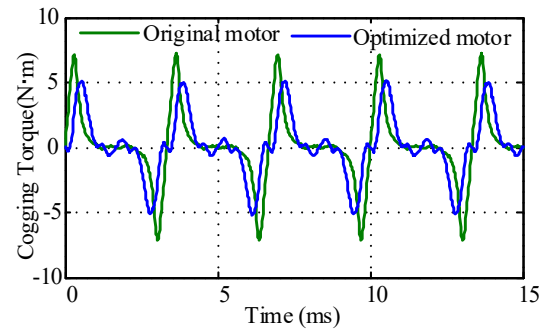

Fig. 14. Cogging torque waveforms of the initial and optimized motors.

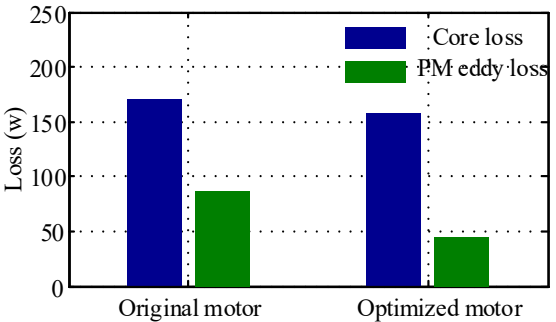

Fig. 15. Core loss and PM eddy loss of original and optimized motors @ 2500 $\mathrm{rpm} / 30 \mathrm{~N} \cdot \mathrm{m}$.

In order to verify the advantages of the optimization, the core loss and PM eddy loss of the original and optimized motors at $3000 \mathrm{rpm} / 25 \mathrm{Nm}$ are analyzed and the results are shown in Fig 15. As shown, the core loss and PM eddy loss of the optimized motor are $7 \%$ and $47 \%$ lower than those of the initial motor, respectively. The main reason is that the thickness of the optimized motor is lower than the initial motor and the eddy current effect is obviously reduced.

In addition, as the core loss and PM eddy loss has been reduced the temperature rise in stator and PMs could also be reduced. A simplified temperature network model as show in Fig. 16 is used in this study to verify the inhibitory effect of loss reduction on temperature rise. As shown, the equivalent thermal resistances of the axle, stator yoke, stator teeth, phase winding, end winding, air, PMs, rotor, housing, and endcap are represented in square. The heat sources in this model include the stator core loss $\left(P_{\text {stator }}\right)$, rotor core loss $\left(P_{\text {rotor }}\right)$, phase winding loss $\left(P_{\mathrm{cu} 1}, P_{\mathrm{cu} 2}, P_{c u 3}\right)$, end winding loss $\left(P_{c u \text { End1 }}, P_{c u \text { End1 } 1}\right)$, and PM eddy current loss $\left(P_{\mathrm{PM}}\right)$. The temperature rise of the stator and PMs can be calculated based on this temperature network.

The simulated temperature rise results in the stator and PMs of the original and optimized motors at $2500 \mathrm{rpm} / 30 \mathrm{Nm}$ are shown in Fig. 17. As shown, the temperature of stators of original and optimized motors will reach 105 and $102{ }^{\circ} \mathrm{C}$, respectively, and the temperature of PMs of original and optimized motors will reach 74 and $67{ }^{\circ} \mathrm{C}$ respectively. Thus, the temperature rise results in the stator and PMs of the motor have been effectively reduced after optimization.

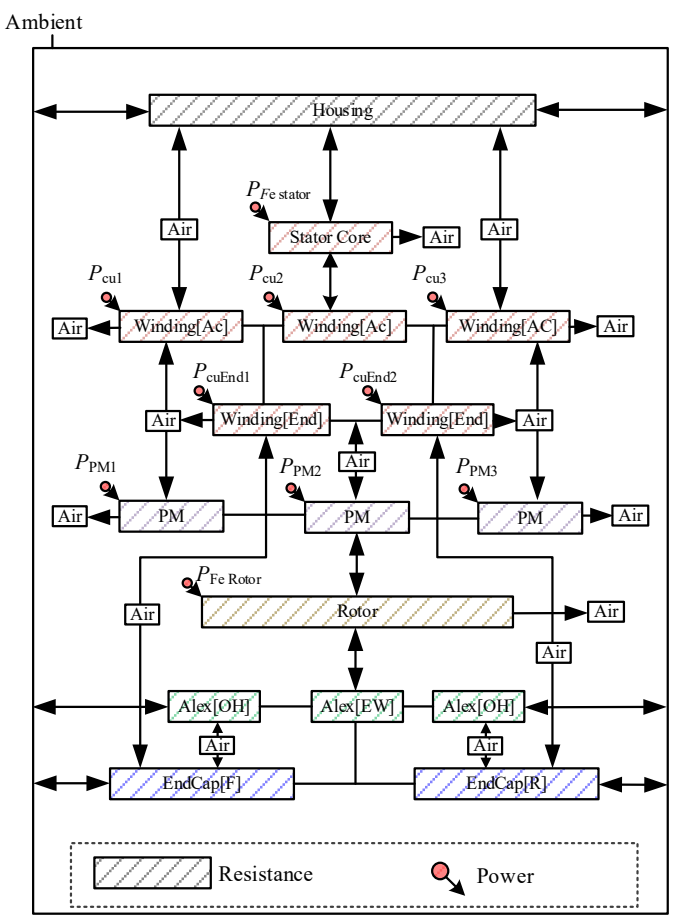

Fig. 16. Thermal network model of the PMSM.

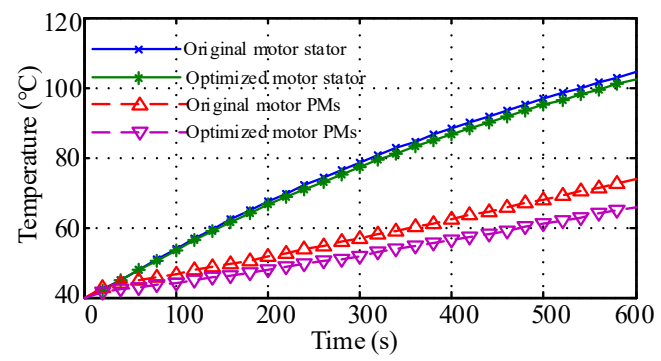

Fig. 17. Simulation temperature rise results in stator and PMs of the PMSM.

\section{Maximum Torque Capability}

The acceleration and climbing capabilities are two essential performances for a drive motor. They directly depend on the overload capability of the motors. Fig. 18 shows the averages and ripples of electromagnetic torques of two motors versus current densities. As shown, when the phase current density is lower than $6 \mathrm{~A} / \mathrm{mm}^{2}$, the torque of optimized motor is close to the that of the initial motor. However, with the increase of the 
phase current, the torque of the optimized motor is relatively larger. When the current density reaches to $18 \mathrm{~A} / \mathrm{mm}^{2}$, the torque of optimized motor is $6.8 \%$ larger than that of the initial motor. This means that the over road capability of optimized motor is much better. Meanwhile, the torque ripple of optimized motor is obviously lower than that of the initial motor.

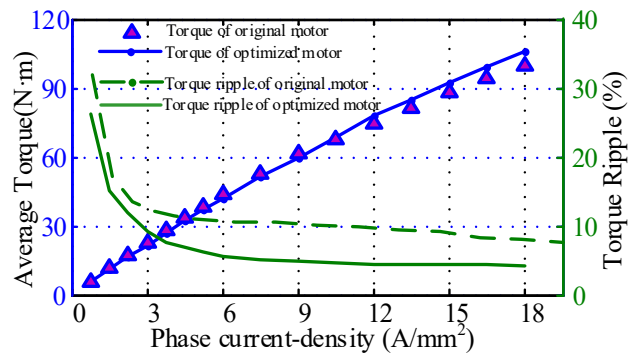

Fig. 18. Average torque and torque ripple versus current densities of original motor and optimized motor@2500 r/min.

\section{EXPERIMENTAL VALIDATIONS}

In this section, in order to validate the performances of the designed PMSM, a prototype has been manufactured. Various experiments are carried out and analyzed as follows.

\section{A. Test Bench}

Fig. 19 shows the test benches. Fig. 19(a) is a test bench for the measurement of the no-load phase back-EMF including a load motor, a torque sensor, and an oscilloscope. The test bench for the measurement of dynamic performance includes a power source, a torque sensor, a magnetic, and a motor controller based on DSP-2812, as shown in Fig 19(b).

\section{B. No-Load Back-EMF Waveforms}

Figs. 20 and 21 compare the measured and FEA-predicted no-load phase back-EMF waveforms. It is evident that the proposed PMSM has sinusoidal and symmetric back-EMFs, which agree with the FEA simulated results. The insignificant discrepancies between the experimental and simulated results mainly result from the end effect and manufacture tolerances.

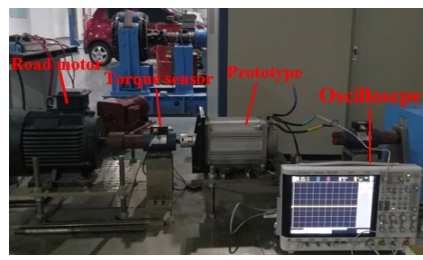

(a)

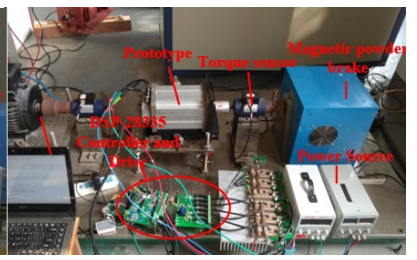

(b)
Fig.19. Experimental platform configuration. (a) Test bench for the measurement of the no-load phase back-EMF. (b) Test bench for the measurement of dynamic performance.

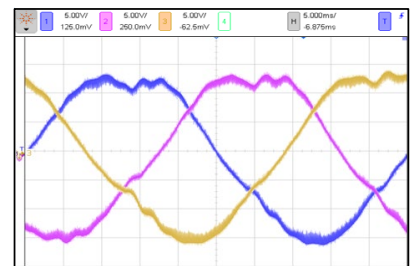

Fig.20. Measured no-load phase back-EMF waveforms at $500 \mathrm{r} / \mathrm{min}$.

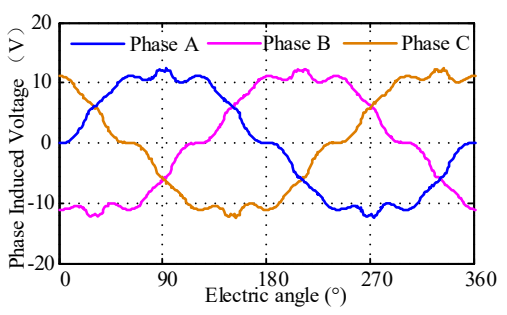

Fig.21. Simulated no-load phase back-EMF waveforms at $500 \mathrm{rpm}$.

\section{Maximum Torque and Efficiency}

To verify the torque capability of the optimized motor, the torque-current curves at $2500 \mathrm{rpm}$ predicted by FEA method and experiment are given in Fig. 22. As shown, the output torque of experiment is $3-5 \%$ smaller than that of the FEA predictions. The reason for these small differences is that the air resistance and friction resistance are negligible in the simulation process. Overall, the experimental results are in good agreement with the simulation.

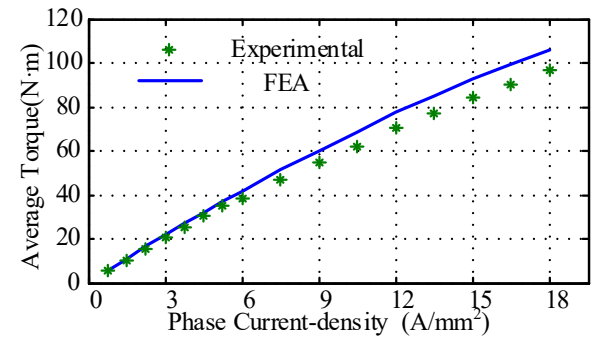

Fig.22. Measured average torque versus phase current @2500r/min.

Fig. 23 shows the measured efficiency map which covers the main working range of the proposed motor under the DC link voltage of $72 \mathrm{~V}$. The maximum efficiency can reach $95.5 \%$. When the EV climbs a slope with a $6 \%$ slope at $40 \mathrm{~km} / \mathrm{h}$ the efficiency can reach $88 \%$. Combined with the speed and altitude curves of the EV route in Fig. 2, the overall efficiency of the patrol EV to complete a patrol is $87 \%$.

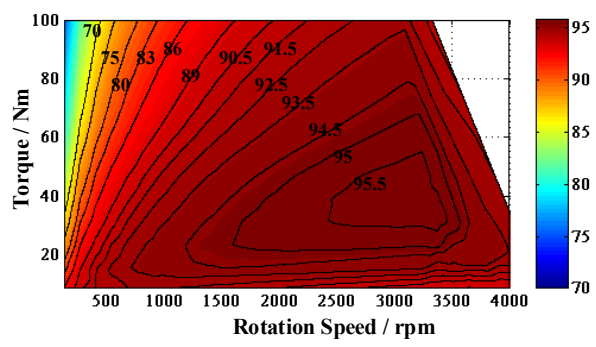

Fig.23. Measured efficiency map of the designed PMSM.

\section{CONCLUSION}

A PMSM was designed and optimized for a campus patrol EV in this work. To meet the practical requirements, the main design parameters of the PMSM were matched by using dynamic calculation method. Firstly, the parameters of the EV were collected, and then the road traffic information of the campus patrol vehicle was collected. The calculation of the main design parameters of the motor was completed based on these data. To reduce the torque ripple, the coreless, and the mass of PM material, the structure of PM, stator slot size, airgap length and rotor structure of the PMSM were optimized. The FEA method and thermal network model was used to verify the 
effectiveness of the optimization. Finally, the static performance, torque and efficiency performance of the prototype were verified experimentally. The results of torque and efficiency map show that the prototype meets the requirements of the campus patrol $\mathrm{EV}$. The research of this paper can provide useful reference for parameter matching and structural optimization design of drive motor of EVs used in specific road conditions.

\section{REFERENCES}

[1] J. J. Justo, F. Mwasilu, E. Kim, J. Kim, H. H. Choi and J. Jung, "Fuzzy model predictive direct torque control of IPMSMs for electric vehicle applications," IEEE-ASME Trans. Mechatron., 2017, 22(4): 1542.

[2] M. Khayamy, and H. Chaoui, "Current sensorless MTPA operation of interior pmsm drives for vehicular applications," IEEE Trans. Veh. Technol., vol. 67, pp. $6872-6881,2018$

[3] X. Sun, C. Hu, G. Lei, Y. Guo, and J. Zhu, "State feedback control for a pm hub motor based on Grey wolf optimization algorithm, "IEEE Trans. Power Electron., pp. 1-1, 2019.

[4] Z. Shi, X. Sun, Y. Cai, Z. Yang, G. Lei, Y. Guo, and J. Zhu, "Torque analysis and dynamic performance improvement of a PMSM for EVs by skew angle optimization," IEEE Trans. Appl. Supercon., vol. 29, no. 2, pp. 1-5, 2019.

[5] V. Ruuskanen, J. Nerg, J. Pyrhoenen, S. Ruotsalainen, and R. Kennel, "Drive Cycle Analysis of a Permanent-Magnet Traction Motor Based on Magnetostatic Finite-Element Analysis," IEEE Trans. Veh. Technol., vol. 64, pp. 1249-1254, 2015.

[6] P. H. Nguyen, E. Hoang and M. Gabsi, "Performance synthesis of permanent-magnet synchronous machines during the driving cycle of a hybrid electric vehicle," IEEE Trans. Veh. Technol., vol. 60, pp. 1991-1998, 2011.

[7] O. Farrok, M. R. Islam, Y. Guo, J. Zhu, and W. Xu, "A novel design procedure for designing linear generators, "IEEE Trans. Ind. Electron., vol. 65 , no. 2, pp. 1846-1854, 2018

[8] O. Farrok, M. R. Islam, M. R. I. Sheikh, and W. Xu, "A new optimization methodology of the linear generator for wave energy conversion systems," in 2016 IEEE International Conference on Industrial Technology (ICIT), 2016, pp. 1412-1417.

[9] A. G. Sarigiannidis, M. E. Beniakar and A. G. Kladas, "Fast adaptive evolutionary PM traction motor optimization based on electric vehicle drive cycle," IEEE Trans. Veh. Technol., vol. 66, pp. 5762-5774, 2017.

[10] V. Ruuskanen, J. Nerg, J. Pyrhönen, S. Ruotsalainen, and R. Kennel, "drive cycle analysis of a permanent-magnet traction motor based on magneto static finite-element analysis," IEEE Trans. Veh. Technol., vol. 64, no. 3, pp. 1249-1254, 2015.

[11] G. Feng, C. Lai, K. L. V. Iyer, and N. C. Kar, "Improved high-frequency voltage injection based permanent magnet temperature estimation for PMSM condition monitoring for EV applications," IEEE Trans. Veh. Technol., vol. 67, pp. 216-225, 2018.

[12] C. López-Torres, A. G. Espinosa, J. Riba, and L. Romeral, "Design and optimization for vehicle driving cycle of rare-earth-free SynRM based on coupled lumped thermal and magnetic networks," IEEE Trans. Veh. Technol, vol. 67, no. 1, pp. 196-205, 2018

[13] C. Ma, Q. Li, Q. Liu, D. Wang, J. Gao, H. Tang, and Y. Sun, "Sound quality evaluation of noise of hub permanent-magnet synchronous motors for electric vehicles," IEEE Trans. Ind. Electron., vol. 63, pp. 5663-5673, 2016.

[14] K. Ahn, A. E. Bayrak and P. Y. Papalambros, "Electric vehicle design optimization: integration of a high-fidelity interior-permanent-magnet motor model," IEEE Trans. Veh. Technol., vol. 64, pp. 3870-3877, 2015.

[15] Z. Y. Gu, K. Wang, Z. Q. Zhu, Z. Z. Wu, C. Liu, and R. W. Cao, "Torque improvement in five-phase unequal tooth SPM machine by injecting third harmonic current," IEEE Trans. Veh. Technol., vol. 67, pp. 206-215, 2018.

[16] K. T. Chau, C. C. Chan and C. Liu, "Overview of permanent-magnet brushless drives for electric and hybrid electric vehicles," IEEE Trans. Ind. Electron., vol. 55, pp. 2246-2257, 2008.

[17] D. Brown, B. M. Ma and Z. M. Chen, "Developments in the processing and properties of NdFeB-type permanent magnets," J. Magn. Magn. Mater., vol. 248, pp. 432-440, 2002

[18] L. Rovere, A. Formentini, A. Gaeta, P. Zanchetta, and M. Marchesoni, "Sensorless finite-control set model predictive control for IPMSM drives," IEEE Trans. Ind. Electron., vol. 63, pp. 5921-5931, 2016.

[19] Y. Li, S. Zhu, Y. Li and Q. Lu, "Temperature prediction and thermal boundary simulation using Hardware-in-Loop method for permanent magnet synchronous motors," IEEE-ASME Trans. Mechatron., 2016, 21(1): 276.

[20] W. Wang, J. Zhang and M. Cheng, "A dual-level hysteresis current control for one five-leg vsi to control two PMSMs," IEEE Trans. Pow. Electron., vol. 32, pp. 804-814, 2017.

[21] C. Shi, Y. Tang and A. Khaligh, "A single-phase integrated onboard battery charger using propulsion system for plug-in electric vehicles," IEEE Trans. Veh. Technol., vol. 66, pp. 10899-10910, 2017.

[22] G. Lei, J. G. Zhu, and Y. G. Guo, Multidisciplinary Design Optimization Methods for Electrical Machines and Drive Systems, Springer-Verlag Berlin Heidelberg, ISBN: 978-3-662-49269-7, 2016.

[23] T. Nakata, M. Sanada, S. Morimoto, and Y. Inoue, "Automatic design of IPMSMs using a genetic algorithm combined with the Coarse-Mesh FEM for enlarging the high-efficiency operation area," IEEE Trans. Ind. Electron., vol. 64, no. 12, pp. 9721-9728, 2017.

[24] H.-S. Seol, J. Lim, D.-W. Kang, J. S. Park, and J. Lee, "Optimal design strategy for improved operation of IPM BLDC motors with low-resolution hall sensors," IEEE Trans. Ind. Electron., vol. 64, no. 12, pp. 9758-9766, 2017.

[25] D. Mingardi and N. Bianchi, "Line-Start PM-assisted synchronous motor design, optimization, and tests," IEEE Trans. Ind. Electron., vol. 64, no. 12, pp. 9739-9747, 2017.

[26] H. A. Moghaddam, A. Vahedi, and S. H. Ebrahimi, "Design optimization of transversely laminated synchronous reluctance machine for flywheel energy storage system using response surface methodology," IEEE Trans. Ind. Electron., vol. 64, no. 12, pp. 9748-9757, 2017.

[27] K. Sindhya, A. Manninen, K. Miettinen, and J. Pippuri, "Design of a permanent magnet synchronous generator using interactive multi-objective optimization," IEEE Trans. Ind. Electron., vol. 64, no. 12, pp. 9776-9783, 2017.

[28] S. S. R. Bonthu, A. K. M. Arafat, and S. Choi, "Comparisons of rareearth and rare-earth-free external rotor permanent magnet assisted synchronous reluctance motors," IEEE Trans. Ind. Electron., vol. 64, no. 12, pp. 9729-9738, 2017.

[29] K. T. Chau, Electric vehicle machines and drives: design, analysis and application, New York. John Wiley\& Sons (Asia), ch. 4, pp 93-96, 2015.

[30] G. Lei, J. Zhu, Y. Guo, K. Shao, and W. Xu, "Multi-objective sequential design optimization of PM-SMC motors for six sigma quality manufacturing," IEEE Trans. Magn, vol. 50, no. 2, 2014, Art. no. 7017704.

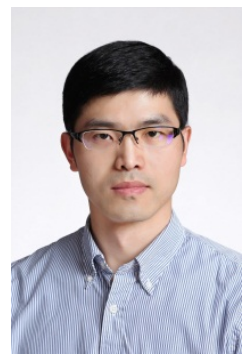

Xiaodong Sun (M'12-SM'18) received the B.Sc. degree in electrical engineering, and the M.Sc. and Ph.D. degrees in control engineering from Jiangsu University, Zhenjiang, China, in 2004, 2008, and 2011, respectively.

Since 2004, he has been with Jiangsu University, where he is currently a Professor with the Automotive Engineering Research Institute. From 2014 to 2015, he was a Visiting Professor with the School of Electrical, Mechanical, and Mechatronic Systems, University of Technology Sydney, Sydney, Australia. His current teaching and research interests include electrical machines and drives, drives and control for electric vehicles, and intelligent control. $\mathrm{He}$ is the author or coauthor of more than 80 refereed technical papers and one book, and he is the holder of 36 patents in his areas of interest.

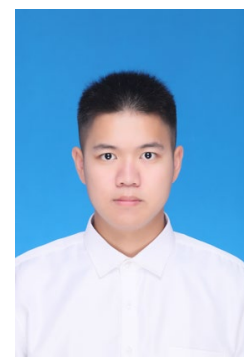

Zhou Shi was born in Nantong, Jiangsu, China, in 1993. He received the B.S. degree in vehicle engineering from Jiangsu University, Zhenjiang, China, in 2016, and he is currently working toward the Ph.D. degree in Jiangsu University, Zhenjiang, China.

His current research interests include design, optimization, magnetic equivalent circuits modeling, control, and loss analysis of permanent magnet synchronous motors for automobile application. 
Gang Lei (M'14) received the B.S. degree in Mathematics from Huanggang Normal University, China, in 2003, the M.S. degree in Mathematics and Ph.D. degree in Electrical Engineering from Huazhong University of Science and Technology, China, in 2006 and 2009, respectively. He is currently a senior lecturer at the School of Electrical and Data Engineering, University of Technology Sydney (UTS), Australia. His research interests include design optimization and control of electrical drive systems and renewable energy systems.

Youguang Guo (S'02-M'05-SM'06) received the B.E. degree from Huazhong University of Science and Technology, China in 1985, the

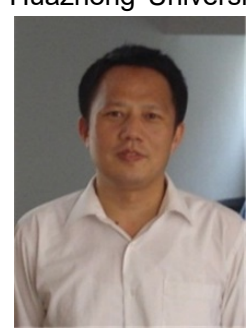

M.E. degree from Zhejiang University, China in 1988, and the Ph.D. degree from University of Technology, Sydney (UTS), Australia in 2004, all in electrical engineering. $\mathrm{He}$ is currently an associate professor at the School of Electrical and Data Engineering, University of Technology Sydney (UTS). His research fields include measurement and modeling of properties of magnetic materials, numerical analysis of electromagnetic field, electrical machine design optimization, power electronic drives and control.

Jianguo Zhu (S'93-M'96-SM'03) received the B.E. degree in 1982 from Jiangsu Institute of Technology, Jiangsu, China, the M.E. degree in 1987

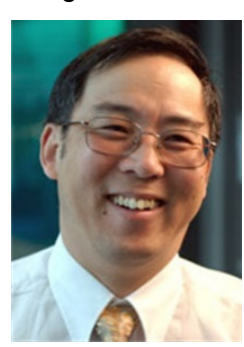

from Shanghai University of Technology, Shanghai, China, and the Ph.D. degree in 1995 from the University of Technology Sydney (UTS), Sydney, Australia, all in electrical engineering. He was appointed a lecturer at UTS in 1994 and promoted to full professor in 2004 and Distinguished Professor of Electrical Engineering in 2017. At UTS, he has held various leadership positions, including the Head of School for School of Electrical, Mechanical and Mechatronic Systems and Director for Centre of Electrical Machines and Power Electronics. In 2018, he joined the University of Sydney, Australia, as a full professor and Head of School for School of Electrical and Information Engineering. His research interests include computational electromagnetics, measurement and modelling of magnetic properties of materials, electrical machines and drives, power electronics, renewable energy systems and smart micro grids. 